\title{
Outcomes of Delayed Sternal Closure in Paediatric Cardiac Surgical Patients-A Prospective Single Centre Study
}

\author{
Prateek Vaswani ${ }^{1}$ Manoj Kumar Sahu ${ }^{2}$ Challatil Bipin² Sarvesh Pal Singh ${ }^{2}$ \\ Palleti Rajashekar ${ }^{1}$ Velayoudam Devagourou' ${ }^{1}$ Sachin Talwar ${ }^{1}$ \\ 1Department of Cardiothoracic and Vascular Surgery, \\ Cardiothoracic and Neurosciences Centre, All India Institute of \\ Medical Sciences, New Delhi, India \\ 2Intensive Care for CTVS, CT Centre, Cardiothoracic and \\ Neurosciences Centre, All India Institute of Medical Sciences, \\ New Delhi, India

\begin{abstract}
Address for correspondence Manoj K. Sahu, MD, DNB, Intensive Care for CTVS, Department of CTVS, Cardiothoracic and Neurosciences Centre, All India Institute of Medical Sciences, Room No 5, 7th Floor, New Delhi-110029, India
\end{abstract} \\ (e-mail: drmanojsahu@gmail.com).
}

J Card Crit Care:2020;4:96-103

\begin{abstract}
Keywords

- delayed sternal closure

- open chest management

- pediatric cardiac surgeries

- cardiopulmonary bypass

- ECMO
\end{abstract}

Background Delayed sternal closure (DSC) is being increasingly used as an interim support to help the dysfunctional heart in the road to recovery after complex pediatric cardiac surgeries. The purpose of this study was to assess the conduct of DSC at a tertiary care center.

Methods Between 2018 and 2019, 185 consecutive pediatric patients (below 12 years of age) underwent cardiac surgery at a tertiary care center. The incidence and causes of DSC were noted. The various pre, intra and postoperative factors till discharge or demise were noted and analyzed.

Results In this study, DSC was done in 63 patients (34.05\%) with a median age and weight of 29 days (18-100 days) and $4 \mathrm{~kg}(2-12.3 \mathrm{~kg})$, respectively. Transposition of great arteries (TGA) (41.27\%) constituted the majority, followed by total anomalous pulmonary venous connection (TAPVC) (26.98\%). Myocardial edema (49.21\%) was the most common indication for DSC. Mean duration of open chest was $40.75 \pm$ 18.58 hours. All-cause mortality was $19.05 \%$ (12/63). On multivariate analysis by logistic regression, the independent predictors of mortality were needed for preoperative mechanical ventilation ( $\mathrm{OR} 42.82,95 \% \mathrm{Cl}=4.52-406.03, p<0.001)$ and development of postoperative sepsis (OR 20.07, $95 \% \mathrm{Cl}=2.12-189.80, p=0.002$ ).

Conclusions DSC is a safe and effective technique in the management of complex pediatric cardiac surgeries. It provides assistance to the severely dysfunctional myocardium soon after the surgery and helps in stabilization of hemodynamics with avoidance of postoperative mediastinal compression. Early sternal closure should be considered on the basis of cardiovascular function and/or resolution of primary indication for DSC.

\section{Introduction}

The concept of delayed sternal enclosure (DSC) and open chest management for cardiomediastinal mismatch in adults was first described by Riahi et al in 1975. ${ }^{1}$ Subsequently, many studies have established the

published online

November 6, 2020
DOI https://doi.org/

$10.1055 / \mathrm{s}-0040-1721229$

ISSN 2457-0206. usefulness of DSC in postcardiac surgery both in adults and children. ${ }^{2-34} \mathrm{~A}$ rise has been observed in edema in myocardium postcardiac surgery for the first 24 hours, which causes a decline in coronary reserve. ${ }^{5}$ These effects are more pronounced in the pediatric population, owing to the

(C) 2020. Official Publication of The Simulation Society (TSS), accredited by International Society of Cardiovascular Ultrasound (ISCU).

This is an open access article published by Thieme under the terms of the Creative Commons Attribution-NonDerivative-NonCommercial-License, permitting copying and reproduction so long as the original work is given appropriate credit. Contents may not be used for commercial purposes, or adapted, remixed, transformed or built upon. (https:// creativecommons.org/licenses/by-nc-nd/4.0/)

Thieme Medical and Scientific Publishers Pvt. Ltd., A-12, 2nd Floor, Sector 2, Noida-201301 UP, India 
relatively greater cardiac size with respect to other mediastinal structures and proportionately severe inflammation of cardiopulmonary bypass (CPB) effects on immature pediatric capillaries. ${ }^{5}$ Therefore, early attempted sternal closure often fails due to development of myocardial edema, ventricular dysfunction, and hemodynamically significant arrhythmias, all resulting from cardiac compression which, in turn, causes tamponade effect on cardiopulmonary functioning. Leaving the sternum open immediately after surgery thus improves diastolic filling, coronary perfusion, and myocardial oxygen supply, thereby improving myocardial function. ${ }^{25,6}$ DSC can minimize the rise in intrathoracic, intrapleural, and pericardial pressures. ${ }^{7}$ It can improve ventricular compliance, thereby improving the cardiac filling. Further benefits include rapid mediastinal access for clot evacuation, requirement of electrical cardioversion, and emergency access for establishing extracorporeal membrane oxygenator (ECMO). ${ }^{8}$ The purpose of this study was to evaluate the incidence of DSC in our setup among pediatric cardiac surgery cases, reasons for DSC, and physiologic effects; determine appropriate time for closure; and evaluate the reasons for morbidity and mortality among these patients.

\section{Materials and Methods}

This prospective observational study was conducted on consecutive pediatric patients below 12 years of age undergoing open heart surgery for complex congenital cardiac lesions in 2 of 8 designated cardiac surgical ORs managed with DSC. This study was conducted from May 2018 and April 2019. Informed written consent was taken from parents/guardian before enrolment. The study was approved by the Institute Ethics Committee and performed in the cardiothoracic surgery center at a tertiary care teaching hospital.

\section{Conduct of Delayed Sternal Enclosure (DSC)}

The decision to leave the sternum open was made intraoperatively. The following details concerning DSC were recorded: indication and the time to successful sternal closure.

Chest closure was accomplished by suturing the skin edges with sterile polyurethane transparent membrane (e.g., blood collection bag) and Prolene suture. Povidone iodine ointment was applied and covered with sterile gauze all around over which an occlusive iodine impregnated adhesive dressing was placed.

\section{Sternal Closure Procedure}

This was performed in cardiothoracic ICU under strict aseptic precautions. First, careful detachment of sterile sheet was undertaken from skin and mediastinal devices. The polyurethane bag was detached. Two culture swabs were taken from the inner sternal surfaces for microbial assessment. Excessive adhesiolysis was avoided. The sternal closure was achieved with Ethibond sutures after gentamycin saline irrigation. The skin was closed with interrupted nonabsorbable Prolene sutures. Occlusive dressing was put over povidone iodine ointment with a sterile gauze.

\section{ICU Management}

Patients were kept on mechanical ventilation with invasive monitoring under sedation and paralysis, which was achieved with fentanyl infusion (1-2 mcg/ $/ \mathrm{kg} /$ hour $)$ and cisatracurium infusion at $0.2 \mathrm{mg} / \mathrm{kg} / \mathrm{hour}$ respectively till sternum closure.

Enteral feeding was started approximately 6 hours postsurgery with nasogastric tube, in accordance with our ICU protocol. Loop diuretics were used to achieve cumulative negative fluid balance. The transthoracic echocardiography was done to assess the ventricular contractility, pulmonary pressures, and any residual defects.

\section{Antibiotic Protocol}

Our ICU protocol delineates broad-spectrum antibiotic coverage with piperacillin-tazobactum and vancomycin given as $100 \mathrm{mg} / \mathrm{kg} / \mathrm{q} 8 \mathrm{hrly}$ and $15 \mathrm{mg} / \mathrm{kg} / \mathrm{q} 8 \mathrm{hrly}$, respectively. These were escalated in case of clinical suspicion of sepsis or culture growth of a particular organism, with clinical picture suggestive of worsening status.

\section{Statistical Analysis}

Continuous variables were expressed as mean \pm standard deviation (SD), median with interquartile range, and analyzed using Mann-Whitney test or independent $t$-test as appropriate. Categorical variables were analyzed using Pearson's Chi-square test or Fischer exact $t$-test. Changes within continuous variable were assessed by repeated measure ANOVA (analysis of variance), followed by multiple comparisons using Bonferroni test. A $p$ value of less than 0.05 was considered statistically significant. Univariable and stepwise multiple logistic regression with probability of entry " 0.05 " and probability of removal " 0.1 " were performed to assess the independent risk factors for mortality. All statistical analyses were performed using Stata-14 (StataCorp, 4905, Lake way Drive, College Station, Texas, 77845 , USA).

\section{Results}

During the study period, 63 out of 185 pediatric patients who underwent DSC after congenital cardiac operations were included in this study. Incidence of DSC in our study population was found to be $34 \%(63 / 185)$, with male children constituting the majority $(49 / 63,77.8 \%)$ and the remaining 14 were females (22.2\%). Majority of patients were under 1 month of age with a median age of 29 days (18-100 days). Sternum was left open in the OR in all 63 patients with or without a sternal closure trial. Majority of patients were under 6 months of age $(82.54 \%, 52 / 63)$, with more than half under 1 month of age $(57.14 \%, 36 / 63)$.

The preoperative comprehensive cardiac diagnoses for all these children are delineated in - Table 1. Arterial switch operation (ASO) constituted the majority (25/63, $39.68 \%$ ), followed by total anomalous pulmonary venous connection (TAPVC) repair $(17 / 63,26.98 \%)$. One patient of dextro-transposition of great arteries (D-TGA) with ventricular septal defect and left ventricular outflow tract obstruction was managed with Rastelli surgery. 
Table 1 Comprehensive cardiac diagnosis of DSC patients

\begin{tabular}{|c|c|c|c|}
\hline S No. & Diagnosis & $\begin{array}{l}\text { Number of patients } \\
\text { (total } n=63 \text { ) }\end{array}$ & $\begin{array}{l}\text { Percentage } \\
\text { (\%) }\end{array}$ \\
\hline \multirow[t]{5}{*}{1} & D-TGA & 26 & 41.27 \\
\hline & - With intact ventricular septum without BAS & - 13 & - 20.63 \\
\hline & - With VSD/ASD & - 9 & - 14.29 \\
\hline & - Post BAS & $\cdot 3$ & - 4.76 \\
\hline & - With VSD and LVOTO & - 1 & - 1.59 \\
\hline \multirow[t]{5}{*}{2} & TAPVC & 17 & 26.98 \\
\hline & - Supracardiac & $\cdot 7$ & - 11.11 \\
\hline & - Cardiac & - 5 & - 7.94 \\
\hline & - Mixed & $\cdot 3$ & - 4.76 \\
\hline & - Infracardiac & $\cdot 2$ & - 3.17 \\
\hline \multirow[t]{3}{*}{3} & DORV & 5 & 7.94 \\
\hline & - Classical DORV with VSD & $\cdot 4$ & - 6.35 \\
\hline & - DORV with VSD with PS & - 1 & - 1.59 \\
\hline \multirow[t]{3}{*}{4} & TOF & 3 & 4.76 \\
\hline & - Classical TOF & - 1 & - 1.59 \\
\hline & - TOF with PA & $\cdot 2$ & - 3.17 \\
\hline 5 & Interrupted aortic arch & 3 & 4.76 \\
\hline 6 & Truncus Arteriosus & 3 & 4.76 \\
\hline 7 & ALCAPA & 2 & 3.17 \\
\hline 8 & Congenital MR & 1 & 1.59 \\
\hline 9 & Cor-triatriatum & 1 & 1.59 \\
\hline 10 & Type 1 AP Window & 1 & 1.59 \\
\hline 11 & $\begin{array}{l}\text { Intracardiac fungal mass (extending from tip of CVC till TV with TV } \\
\text { vegetation, complication of prolonged CVC placement, thrombus } \\
\text { in left pulmonary artery) }\end{array}$ & 1 & 1.59 \\
\hline
\end{tabular}

Abbreviations: ALCAPA, anomalous left coronary artery from pulmonary artery; AP, aortopulmonary; ASD, atrial septal defect; BAS, balloon atrial septostomy; CVC, central venous catheter; DORV, double outlet right ventricle; LVOTO, left ventricular outflow tract obstruction; MR, mitral regurgitation; PA, pulmonary atresia, PS, pulmonary stenosis; TAPVC, total anomalous pulmonary venous connection; TGA, transposition of great arteries; TOF, tetralogy of Fallot; TV, tricuspid valve; VSD, ventricular septal defect.

The reasons for leaving the sternum open are summarized in - Table 2, with myocardial edema (49.21\%) and nonsurgical hemorrhage $(15.87 \%)$ constituting the majority.

Mean duration of aortic cross-clamp (ACC) was $48.95 \pm$ 18.41 minutes while that of $\mathrm{CPB}$ was $104.40 \pm 42.50$ minutes. In five patients, DHCA at $20^{\circ} \mathrm{C}$ was done with a mean duration of $25.2 \pm 7.78$ minutes. Deep hypothermic circulatory arrest (DHCA) was used in three patients of interrupted aortic arch, one in infracardiac TAPVC, and in one patient with intracardiac mass, extending from superior vena cava to tricuspid valve, with tricuspid valve vegetation having infective thrombus in left pulmonary artery.

Mean duration of open chest was $40.75 \pm 18.58$ hours. Two patients died before sternal closure due to malignant ventricular arrhythmia in one and severe intracerebral bleed in the other. Daily assessment with bedside echocardiography for ventricular contractility, pulmonary pressures, residual lesions, and pericardial collections was done followed by povidone iodine impregnated dressing under aseptic precautions.
Table 2 Indications for delayed sternal closure

\begin{tabular}{|l|l|l|}
\hline $\begin{array}{l}\text { S } \\
\text { No. }\end{array}$ & Indication & $\begin{array}{l}\text { No. of patients } \\
\text { (total } \boldsymbol{n}=63)\end{array}$ \\
\hline 1. & $\begin{array}{l}\text { Myocardial edema causing unstable } \\
\text { hemodynamics on attempted } \\
\text { sternal closure }\end{array}$ & $31(49.21 \%)$ \\
\hline 2. & Nonsurgical hemorrhage & $10(15.87 \%)$ \\
\hline 3. & ECMO & $9(14.29 \%)$ \\
\hline 4. & $\begin{array}{l}\text { Prolonged CPB with pump lung } \\
\text { (decreased lung compliance, } \\
\text { increased airway resistance) }\end{array}$ & $7(11.11 \%)$ \\
\hline 5. & High ionotropic support (VIS $>65)$ & $5(7.94 \%)$ \\
\hline 6. & Conduit compression (Rastelli) & $1(1.59 \%)$ \\
\hline
\end{tabular}

Abbreviations: $\mathrm{CPB}$, cardiopulmonary bypass; ECMO, extracorporeal membrane oxygenator; VIS, vasoactive ionotropic score.

Mean duration of mechanical ventilation (MV) was $142.09 \pm 40.73$ hours with tracheostomy being performed in 11 patients (17.46\%). In cases with prolonged MV or multiple ( $>3$ ) failed extubation attempts, tracheostomy 
was performed. Peritoneal dialysis (PD) was performed in eight patients (12.70\%). The reasons for PD catheter insertion are described in - Table 3.

The mean values of TT3 of $0.81 \pm 0.40$ and TT4 of $39.32 \pm$ 7.63 in the immediate postoperative period, although normal, were significantly lower than predischarge (TT3 $=2.06 \pm 0.62$, $p<0.001$ and TT4 $=73.02 \pm 7.33, p<0.001$ ) values. The mean values of thyroid stimulating hormone (TSH) in the immediate postoperative period $=2.51 \pm 1.19$ and predischarge time $=2.66 \pm 1.15(p=0.13)$ were normal, but higher values were observed at discharge, although it could not approach statistical significance. This could have been due to varied discharge times of the patients. Hypothyroidism was detected in two patients for which thyroxine replacement was done with Ryle's tube at a dose of 5 micrograms per kilogram. All pediatric cases received the micronutrient and calcium, vitamin D and K supplementation as a part of our ICU protocol.

Hemodynamic and metabolic data (blood gas analysis) are reported in - Table 4 . The next table signifies statistical significance of the variations in these parameters in different time intervals ( $\mathbf{- T a b l e ~} \mathbf{5}$ ).

Superficial surgical site infections (SSI) occurred in six (9.5\%) patients. Deep space infection (mediastinitis) was observed in three patients (4.76\%) poststernal closure. Two of them succumbed. One child could be treated with irrigation

Table 3 Causes of peritoneal dialysis

\begin{tabular}{|l|l|l|}
\hline $\begin{array}{l}\text { S. } \\
\text { No. }\end{array}$ & Cause & $n=8$ \\
\hline 1. & $\begin{array}{c}\text { Urine output <0.5 mL/kg/hour with- } \\
\text { - Adequate hemodynamics and } \\
\text { fluid challenge } \\
\text { - Deranged renal function tests } \\
\text { - Severe ventricular dysfunction }\end{array}$ & 4 \\
\hline 2. & Fluid overload & 2 \\
\hline 3. & Severe refractory metabolic acidosis & 1 \\
\hline 4. & Refractory hyperkalemia & 1 \\
\hline
\end{tabular}

of mediastinal cavity with povidone iodine solution and escalation of antibiotics. The sternum was kept open for daily irrigation with warm povidone saline. After the clinical and biochemical parameters settled, the sternal re-fixation was done on the 4th day and skin was closed with interrupted sutures.

Overall, postoperative sepsis developed in 15 patients (23.81\%) out of which 7 patients succumbed. Four developed multiorgan failure, two had mediastinitis, and one manifested disseminated intravascular coagulopathy (DIC). The cultures were positive for growth of pathogens in nine patients of which three yielded Pseudomonas aeruginosa and two had Acinetobacter baumanni from endotracheal secretions, one had E. coli in bloodstream, one had Staphyloccus aureus from central line tip, one had Burkholderia cepacia in blood culture, and one had Klebsiella pneumonia with Enterobacter in urine and bloodstream. The rest of the six patients did not show any culture growth. Antibiotics were given according to institutional protocol.

Mean duration of ICU stay was $21.49 \pm 18.14$ days and that of hospital stay was $29.87 \pm 19.91$ days.

The overall mortality among the patients with DSC was $19 \%(12 / 63)$. The cause for mortality is expressed in - Table 6. Independent $t$-test found factors associated with mortality. These factors have been mentioned in - Table $\mathbf{7}$ for reference. However, multivariate logistic regression revealed the need for preoperative MV (OR 42.82, 95\% CI $=4.52$ 406.03, $p<0.001$ ) and development of postoperative sepsis (OR 20.07, 95\% CI $=2.12-189.80, p=0.002$ ) as independent predictors of mortality.

\section{Discussion}

The first description of disproportionate cardiac and mediastinal cavity was made by Riahi et al in $1975 .{ }^{1}$ Use in pediatric population was popularized by Ott et $\mathrm{al}^{2}$ and in other studies. ${ }^{4}$ The shift in the paradigm from palliative to total correction has led to rise in use of DSC. Jogi and Werner studied

Table 4 Hemodynamic and blood gas parameters (expressed as mean \pm SD)

\begin{tabular}{|l|l|l|l|l|l|}
\hline Parameters & IPO & BSC & ASC & ASC 3 & ASC 12 \\
\hline $\begin{array}{l}\text { HR } \\
\text { per minute) }\end{array}$ & $150.82 \pm 24.13$ & $139.23 \pm 15.59$ & $142.54 \pm 15.27$ & $143.34 \pm 15.68$ & $138.84 \pm 15.10$ \\
\hline $\begin{array}{l}\text { SBP } \\
(\mathrm{mm} \mathrm{Hg})\end{array}$ & $68.93 \pm 12.44$ & $77.90 \pm 8.16$ & $75.30 \pm 7.74$ & $74.75 \pm 7.86$ & $78.44 \pm 7.92$ \\
\hline $\begin{array}{l}\text { DBP } \\
(\mathrm{mm} \mathrm{Hg})\end{array}$ & $42.69 \pm 9.28$ & $47.64 \pm 6.35$ & $47.44 \pm 6.28$ & $47.52 \pm 6.38$ & $47.66 \pm 6.16$ \\
\hline $\begin{array}{l}\mathrm{CVP} \\
\left(\mathrm{cm} \mathrm{H} \mathrm{H}_{2} \mathrm{O}\right)\end{array}$ & $11.46 \pm 3.1$ & $10.43 \pm 1.44$ & $11.39 \pm 1.21$ & $11.49 \pm 1.27$ & $10.39 \pm 1.08$ \\
\hline $\mathrm{pH}$ & $7.29 \pm 0.02$ & $7.38 \pm 0.01$ & $7.33 \pm 0.02$ & $7.34 \pm 0.02$ & $7.39 \pm 0.02$ \\
\hline Lactates & $6.47 \pm 2.30$ & $2.88 \pm 1.09$ & $3.18 \pm 1.57$ & $3.06 \pm 1.54$ & $3.09 \pm 1.30$ \\
\hline Base deficit & $-5.18 \pm 2.29$ & $-2.81 \pm 1.86$ & $-3.47 \pm 1.32$ & $-3.78 \pm 1.45$ & $-3.40 \pm 1.31$ \\
\hline $\mathrm{CT}\left({ }^{\circ} \mathrm{C}\right)$ & $36.40 \pm 1.50$ & $36.42 \pm 0.88$ & $36.38 \pm 1.02$ & $36.42 \pm 1.02$ & $36.41 \pm 0.99$ \\
\hline PT $\left({ }^{\circ} \mathrm{C}\right)$ & $26.78 \pm 1.71$ & $28.99 \pm 0.91$ & $29.03 \pm 1.09$ & $29.01 \pm 1.30$ & $29.00 \pm 1.05$ \\
\hline
\end{tabular}

Abbreviations: ASC 12, after sternal closure 12 hours; ASC 3, after sternal closure 3 hours; ASC, after sternal closure; BSC, before sternal closure; CT, core temperature; CVP, central venous pressure; DBP, diastolic blood pressure; HR, heart rate; IPO, immediate postoperative; PT, peripheral temperature; SBP, systolic blood pressure; SD, standard deviation. 
Table 5 Hemodynamic and blood gas parameters comparison at different time intervals

\begin{tabular}{|l|l|l|l|l|}
\hline Parameters & $\begin{array}{l}\text { IPO vs. BSC } \\
p \text { value }\end{array}$ & $\begin{array}{l}\text { BSC vs. ASC } \\
p \text { value }\end{array}$ & $\begin{array}{l}\text { BC vs. ASC } \\
p \text { value }\end{array}$ & $\begin{array}{l}\text { BC vs. ASC 12 } \\
p \text { value }\end{array}$ \\
\hline HR & $<0.001$ & $<0.001$ & $<0.001$ & 1 \\
\hline SBP & $<0.001$ & $<0.001$ & $<0.001$ & 0.174 \\
\hline DBP & $<0.001$ & 1 & 1 & 1 \\
\hline CVP & 0.024 & $<0.001$ & $<0.001$ & 1 \\
\hline pH & $<0.001$ & $<0.001$ & $<0.001$ & 0.108 \\
\hline Lactates & $<0.001$ & 1 & 1 & 1 \\
\hline Base deficit & $<0.001$ & 0.173 & 0.006 & 0.628 \\
\hline CT & 1 & 1 & 1 & 1 \\
\hline PT & $<0.001$ & 1 & 1 & 1 \\
\hline
\end{tabular}

Abbreviations: ASC 12, after sternal closure 12 hours; ASC 3, after sternal closure 3 hours; ASC, after sternal closure; BSC, before sternal closure; CT, core temperature; CVP, central venous pressure; DBP, diastolic blood pressure; HR, heart rate; IPO, immediate postoperative; PT, peripheral temperature; SBP, systolic blood pressure.

Table 6 Causes of death

\begin{tabular}{|l|l|l|}
\hline \multirow{2}{*}{$\begin{array}{l}\text { S. } \\
\text { No. }\end{array}$} & Cause & $n=12$ \\
\hline \multirow{2}{*}{1.} & Sepsis- & 7 \\
\cline { 2 - 3 } & Multiple organ dysfunction syndrome & 4 \\
\cline { 2 - 3 } & Mediastinitis & 2 \\
\cline { 2 - 3 } & $\begin{array}{l}\text { Disseminated intravascular } \\
\text { coagulopathy }\end{array}$ & 1 \\
\hline 2. & $\begin{array}{l}\text { Refractory cardiogenic shock with poor } \\
\text { biventricular function }\end{array}$ & 2 \\
\hline 3. & Pulmonary hypertensive crisis & 1 \\
\hline 4. & Severe intracranial hemorrhage & 1 \\
\hline 5. & Refractory ventricular arrhythmia & 1 \\
\hline
\end{tabular}

the detrimental effects of raised intrapericardial pressures while attempting premature sternal closure on transmural end-diastolic pressures of both the ventricles. ${ }^{9}$ They seem to increase, leading to compensatory rise in atrial pressures, affecting atrial filling and, thus, falling end-diastolic volumes of the ventricles, translating into poor systemic perfusion. This has been demonstrated in echo-based ${ }^{10}$ and catheter-based studies. ${ }^{5}$ The reduced contractile force of myocardium in isovolumetric phase and inadequate coronary reserve due to poorly compliant ventricles has also been proposed. ${ }^{11}$ However, keeping sternum open witnessed rise in cardiac index by $59 \%$ and in systolic blood pressures up to $18 \%{ }^{12,13}$ All this have led to increased applicability of DSC in various centers.

In our study the incidence of DSC was $34 \%$ which is comparable to the studies by Samir et $\mathrm{al}^{14}(45 \%)$ and McElhinney et $\mathrm{a}^{15}(22 \%)$. TGA and hypoplastic left heart syndrome were the most common pathologies which led to DSC in previous studies. ${ }^{8,16-171819}$ ASO (41.27\%) and TAPVC repair (26.98\%) constituted the majority in our study.

The indications for DSC were multifactorial, with majority being myocardial edema, nonsurgical hemorrhage, and
ECMO, which correlated well with other studies. ${ }^{18-20}$ Lower incidences of sepsis and mortality were observed in patients managed by DSC, where decision was taken electively in the OR compared with those opened on emergency basis in the ICU. ${ }^{14,21}$ Therefore, the factors predicting DSC are essential to be kept in mind while management of DSC in the OR. In this study also, the decision for DSC was taken in the OR itself with no events of emergency sternal opening in the ICU.

The wide variation in weight and duration of DSC preclude a standard calculation, however, as an institutional policy for complex cardiac surgeries, we follow a total cumulative fluid balance of 75 to $100 \mathrm{~mL} / \mathrm{kg}$ before attempted sternal closure. The importance of negative fluid balance has been highlighted in studies by Mills et al. ${ }^{22}$

The success of DSC could be demonstrated by significant improvement seen in hemodynamic and blood gas parameters as seen in - Tables $\mathbf{4}$ and $\mathbf{5}$. Also, the transient hemodynamic alterations around the sternal closure time, which improved after 12 hours of sternal closure (-Table 5), correlated well with other studies. ${ }^{22-24}$ However, the inotropic requirement and urine output remain unchanged. Horvath et al also demonstrated the decline in oxygen saturations; however, there was immediate discontinuation of neuromuscular blockade, which could have contributed to this effect. ${ }^{24}$ In this study, the muscle relaxants were continued till 12 hours after the sternal closure; therefore, no sudden unexpected metabolic surges interfered with assessment.

There has also been postulated effects of complex pediatric cardiac surgeries on hypothalamic-pituitary-thyroid axis. The correction of complex lesions, institution of profound hypothermia for arrest of circulation, higher dose of vasopressor agents, and excess use of blood components in perioperative period have been proposed factors affecting this axis. ${ }^{25}$ This effect is pronounced in pediatric age group, owing to immature central nervous system. The use of iodine containing ointment and adhesive drapes with iodine containing mediastinal irrigation may contribute further to 
Table 7 Comparison of variables between survivors and nonsurvivors

\begin{tabular}{|c|c|c|c|c|}
\hline S. No. & Variable & Survivor $(n=51)$ & Nonsurvivor $(n=12)$ & $p$ value \\
\hline 1. & Preoperative MV & 5 & 8 & $<0.001$ \\
\hline 2. & Preoperative Sepsis & 6 & 4 & 0.066 \\
\hline 3. & Preoperative inotropes & 3 & 1 & 0.754 \\
\hline 4. & $\begin{array}{l}\text { RACHS-1 score } \\
(\text { mean } \pm \text { SD) }\end{array}$ & $2.23 \pm 0.51$ & $4.33 \pm 0.65$ & $<0.001$ \\
\hline 5. & $\begin{array}{l}\text { Age (days) } \\
\text { Median (Interquartile range) }\end{array}$ & $89(45-315)$ & $87.5(38.25-505.25)$ & 0.053 \\
\hline 6. & $\begin{array}{l}\text { Duration of open sternum } \\
\text { (hours) (mean } \pm \text { SD) }\end{array}$ & $33.37 \pm 6.63$ & $78.4 \pm 14.54$ & $<0.001$ \\
\hline 7. & $\begin{array}{l}\text { ACC (minutes) } \\
(\text { mean } \pm \text { SD) }\end{array}$ & $43.95 \pm 16.04$ & $69 \pm 15.01$ & $<0.001$ \\
\hline 8. & $\begin{array}{l}\text { CPB (minutes) } \\
(\text { Mean } \pm \text { SD) }\end{array}$ & $104.22 \pm 45.01$ & $105.17 \pm 31.20$ & 0.9451 \\
\hline 9. & Postoperative re-exploration & 5 & 9 & $<0.001$ \\
\hline 10. & $\begin{array}{l}\text { Postoperative MV (hours) } \\
\text { (mean } \pm \text { SD) }\end{array}$ & $130.78 \pm 19.44$ & $220.67 \pm 22.48$ & $<0.001$ \\
\hline 11. & Postoperative sepsis & 8 & 7 & 0.002 \\
\hline 12. & $\begin{array}{l}\text { Mediastinitis } \\
\text { (deep space infection) }\end{array}$ & 1 & 2 & 0.031 \\
\hline
\end{tabular}

Abbreviations: ACC, aortic cross-clamp; CPB, cardiopulmonary bypass; MV, mechanical ventilation; RACHS, risk assessment for congenital heart surgery; SD, standard deviation.

iodine absorption from skin or pericardial cavity causing hypothyroidism. The trend in values of TT3, TT4 and TSH as summarized in results correlates well with the study by Kovacikova et $\mathrm{al}^{25}$ and demonstrated the safety of using iodine-containing ointments and impregnated dressing materials without any effects of hypothyroidism in pediatric patients.

Sternal closure has been attempted by many techniques including skin approximation, application of sternal retractor, silicone sheet, mediastinal packs, sternal stent, ${ }^{8}$ and bootlace technique. ${ }^{26}$ Staged closure using a binder clip was described by Fuchigami et al. ${ }^{27}$ Tanaka et al revealed a semisternal closure with bioresorbable osteosynthesis device. ${ }^{28}$ This is not available at our center. We used the blood collection bag, which can be used as a polyurethane sheet for covering the open sternum in the management of DSC. It is readily available, sterile, transparent, cost-effective, and allows for prompt mediastinal inspection.

The assessment for timing of sternal closure was guided by hemodynamic stability, absence of significant arrhythmia, desirable diuresis achievement, optimal blood gas readings, acceptable ionotropic support, and adequate/improved ventricular contractility on echocardiographic assessment.

Sternal closure time did not significantly influence our rate of deep sternal wound infection. In this study, three patients $(4.76 \%)$ developed mediastinitis. The incidence of mediastinitis due to delayed sternal closure ranges from $1.8 \%$ to $5.6 \%$ in various studies. ${ }^{8,14,15,19}$ Ozker et al revealed $10.5 \%$ incidence of mediastinitis with sternal closure times of $2.9 \pm 2.3$ days. ${ }^{19}$ The lower incidence of mediastinitis in our study could be due to earlier closure of sternum in our patients with a mean of less than 2 days.
Two of these three patients succumbed to septic shock with multiorgan failure. However, superficial SSI was seen in six cases (9.5\%), which responded to conservative measures of topical saline irrigation, daily dressing under aseptic precautions, debridement, and secondary skin suturing, with none of them developing deep space infection. This SSI rate is almost 50\% less than that reported in a retrospective study of STS database by Nelson-McMillan et al with $18.7 \%$ incidence. ${ }^{29}$ Many authors have reported higher incidence of infection with a longer period of open chest. ${ }^{713}$ However, we believe that repeated episodes of sternal closure attempt after premature primary closure would influence the infection rate as was proposed by Harder et al. ${ }^{30}$ There was also no case of delayed sternal wound dehiscence requiring re-fixation in our study.

There has been observed a four-fold rise in blood stream sepsis post DSC. ${ }^{31,32}$ Ozker $^{19}$ and colleagues reported 52.6\% and Elassal et $\mathrm{al}^{20}$ in their study described a sepsis rate of $54.1 \%$. We, however, observed an incidence of $23.81 \%$ in this study which is less than the reported literature. The shorter duration of open sternum could have contributed to lower incidence. Also, there is an observed higher incidence of PD at $12.70 \%$ and tracheostomy at $17.46 \%$, which helped us achieve better fluid balance and earlier weaning from mechanical ventilation, respectively. This contributed to earlier removal of invasive lines and a reduced incidence of sepsis in our study. We did not use modified ultrafiltration routinely in the operating room at our center, hence, we had a low threshold for utilizing PD postoperatively without any observed morbidity. On culture growth, the microbial flora consisted most commonly of Gram negative group of bacteria which correlates well with the published literature. ${ }^{19,21,33}$ 
We observed a mortality of $19 \%$, which is similar to what has been reported in previous studies by many auth ors. ${ }^{8,17,19,20}$ The presence of preoperative MV was found to be contributory to mortality $(p<0.001)$ as was found in other studies. ${ }^{14,20}$ Preoperative sepsis $(p=0.066)$ and inotropic support $(p=0.75)$ did not reach statistical significance as contributor for mortality. Samir et a $\mathrm{l}^{14}$ in their study of 312 neonates found that preoperative inotropic support was not related with mortality as was seen in this study. Sierra et $\mathrm{al}^{34}$ found that risk adjustment for congenital heart surgery (RACHS-1) score $>3$ predicts mortality which corroborated well with our study ( $p<0.001$ ). Longer ACC time translates into a complex cardiac surgery, which has been found to be associated with mortality. ${ }^{17,20,34,35}$ Similar finding was observed in our study ( $p<0.001$ ), however, duration of CPB was not found to be related to mortality $(p=0.94)$. In addition, the postoperative factors such as requirement of re-explorations $(p<0.001)$, duration of DSC $(p<0.001)$, duration of postoperative MV $(p<0.001)$, and development of culture-proven sepsis $(p=0.002)$ and mediastinitis $(p=0.03)$ contributed significantly to mortality, as has been corroborated by other studies. ${ }^{8,14,17,34}$ However, on multivariate analysis, the factors independently contributing to mortality were found to be the need for preoperative MV and development of postoperative sepsis.

\section{Study Limitations}

This is a single center study with a limited study population. It involved three different cardiac surgeons with comparable surgical experience, however, there could be possible variations among intraoperative decision-making for DSC. The overall results and mortality may differ accordingly.

\section{Conclusion}

DSC is being increasingly utilized in adjunct to complex pediatric cardiac surgeries. The decision to manage with DSC should be taken in the OR primarily to avoid complications of emergency sternal opening in the ICU. The improved hemodynamic and metabolic profile with avoidance of mediastinal compression forms the background of DSC. Early sternal closure should be considered on the basis of cardiovascular function and/or resolution of primary indication for DSC.

\section{Financial Support and Sponsorship}

Nil.

\section{Conflicts of Interest}

None declared.

\section{References}

1 Riahi M, Tomatis LA, Schlosser RJ, Bertolozzi E, Johnston DW. Cardiac compression due to closure of the median sternotomy in open heart surgery. Chest 1975;67(1):113-114

2 Ott DA, Cooley DA, Norman JC, Sandiford FM. Delayed sternal closure: a useful technique to prevent tamponade or compression of the heart. Cardiovasc Dis 1978;5(1):15-18
3 Amato J. Review of the rationale for delayed sternal closure. Crit Care Med 2000;28(4):1249-1251

4 Bex JP, de Riberolles C, Lecompte Y, et al. Compression cardiaque lors de la fermeture du sternum après correction de cardiopathies congénitales complexes. Fermeture secondaire. Ann Chir 1980;34(3):198-200

5 Kay PH, Brass T, Lincoln C. The pathophysiology of atypical tamponade in infants undergoing cardiac surgery. Eur J Cardiothorac Surg 1989;3(3):255-260, discussion 260-261

6 del Nido PJ, Williams WG, Villamater J, et al. Changes in pericardial surface pressure during pulmonary hypertensive crises after cardiac surgery. Circulation 1987;76(3 Pt 2) :III93-III96

7 Anderson CA, Filsoufi F, Aklog L, Farivar RS, Byrne JG, Adams DH. Liberal use of delayed sternal closure for postcardiotomy hemodynamic instability. Ann Thorac Surg 2002;73(5):1484-1488

8 Iyer RS, Jacobs JP, de Leval MR, Stark J, Elliott MJ. Outcomes after delayed sternal closure in pediatric heart operations: a 10-year experience. Ann Thorac Surg 1997;63(2):489-491

9 Jögi P, Werner $\mathrm{O}$. Hemodynamic effects of sternum closure after open-heart surgery in infants and children. Scand J Thorac Cardiovasc Surg 1985;19(3):217-220

10 Matsumoto M, Oka Y, Strom J, et al. Application of transesophageal echocardiography to continuous intraoperative monitoring of left ventricular performance. Am J Cardiol 1980;46(1):95-105

11 Fanning WJ, Vasko JS, Kilman JW. Delayed sternal closure after cardiac surgery. Ann Thorac Surg 1987;44(2):169-172

12 Yasa H, Lafçi B, Yilik L, et al. Delayed sternal closure: an effective procedure for life-saving in open-heart surgery. Anadolu Kardiyol Derg 2010;10(2):163-167

13 Furnary AP, Magovern JA, Simpson KA, Magovern GJ. Prolonged open sternotomy and delayed sternal closure after cardiac operations. Ann Thorac Surg 1992;54(2):233-239

14 Samir K, Riberi A, Ghez O, Ali M, Metras D, Kreitmann B. Delayed sternal closure: a life-saving measure in neonatal open heart surgery; could it be predictable? Eur J Cardiothorac Surg 2002;21(5):787-793

15 McElhinney DB, Reddy VM, Parry AJ, Johnson L, Fineman JR, Hanley FL. Management and outcomes of delayed sternal closure after cardiac surgery in neonates and infants. Crit Care Med 2000;28(4):1180-1184

16 Johnson JN, Jaggers J, Li S, et al. Center variation and outcomes associated with delayed sternal closure after stage 1 palliation for hypoplastic left heart syndrome. J Thorac Cardiovasc Surg 2010;139(5):1205-1210

17 Riphagen S, McDougall M, Tibby SM, et al. "Early" delayed sternal closure following pediatric cardiac surgery. Ann Thorac Surg 2005;80(2):678-684

18 Tabbutt S, Duncan BW, McLaughlin D, Wessel DL, Jonas RA, Laussen PC. Delayed sternal closure after cardiac operations in a pediatric population. J Thorac Cardiovasc Surg 1997;113(5):886-893

19 Özker E, Saritaş B, Vuran C, Yörüker U, Ulugöl H, Türköz R. Delayed sternal closure after pediatric cardiac operations; single center experience: a retrospective study. J Cardiothorac Surg 2012;7:102

20 Elassal AA, Eldib OS, Dohain AM, Abdelmohsen GA, Abdalla AH, Al-Radi OO. Delayed sternal closure in congenital heart surgery: a risk-benefit analysis. Heart Surg Forum 2019;22(5):E325-E330

21 Pollock EM, Ford-Jones EL, Rebeyka I, et al. Early nosocomial infections in pediatric cardiovascular surgery patients. Crit Care Med 1990;18(4):378-384

22 Mills KI, van den Bosch SJ, Gauvreau K, et al. Physiologic effects of delayed sternal closure following stage 1 palliation. Cardiol Young 2018;28(12):1393-1403 
23 Main E, Elliott MJ, Schindler M, Stocks J. Effect of delayed sternal closure after cardiac surgery on respiratory function in ventilated infants. Crit Care Med 2001;29(9):1798-1802

24 Horvath R, Shore S, Schultz SE, Rosenkranz ER, Cousins M, Ricci M. Cerebral and somatic oxygen saturation decrease after delayed sternal closure in children after cardiac surgery. J Thorac Cardiovasc Surg 2010;139(4):894-900

25 Kovacikova L, Kunovsky P, Lakomy M, et al. Thyroid function and ioduria in infants after cardiac surgery: comparison of patients with primary and delayed sternal closure. Pediatr Crit Care Med 2005;6(2):154-159

26 Nassar MS, Murtuza B, Hasan A. Bootlace technique for delayed sternal closure in pediatric cardiac surgery. World J Pediatr Congenit Heart Surg 2017;8(3):389-390

27 Fuchigami T, Nishioka M, Akashige T, Higa S, Nagata N. Staged delayed sternal closure using a binder clip after pediatric cardiac surgery. J Card Surg 2016;31(7):464-466

28 Tanaka Y, Miyamoto T, Naito Y, Yoshitake S, Sasahara A, Miyaji K. Sternal semi-closure using a bioresorbable osteosynthesis device: a new method for delayed sternal closure. Surg Today 2018;48(8):748-755

29 Nelson-McMillan K, Hornik CP, He X, et al. Delayed sternal closure in infant heart surgery-the importance of where and when: an analysis of the STS Congenital Heart Surgery Database. Ann Thorac Surg 2016;102(5):1565-1572
30 Harder EE, Gaies MG, Yu S, et al. Risk factors for surgical site infection in pediatric cardiac surgery patients undergoing delayed sternal closure. J Thorac Cardiovasc Surg 2013;146(2):326-333

31 Das S, Rubio A, Simsic JM, et al. Bloodstream infections increased after delayed sternal closure: cause or coincidence. Ann Thorac Surg 2011;91(3):793-797

32 Silvetti S, Landoni G, Castagnola E, Nuri H, Pomé G, Moscatelli A. Antibiotic management for delayed sternal closure following pediatric cardiac surgery: a systematic review of recent literature. J Cardiothorac Vasc Anesth 2020;34(5):1333-1340

33 Woodward CS, Son M, Calhoon J, Michalek J, Husain SA. Sternal wound infections in pediatric congenital cardiac surgery: a survey of incidence and preventative practice. Ann Thorac Surg 2011;91(3):799-804

34 Hurtado-Sierra D, Calderón-Colmenero J, Curi-Curi P, et al. Outcomes of delayed sternal closure in pediatric heart surgery: single-center experience. BioMed Res Int 2018;(e-pub ahead of print). doi: https://doi.org/10.1155/2018/3742362

35 Hakimi M, Walters HL III, Pinsky WW, Gallagher MJ, Lyons JM. Delayed sternal closure after neonatal cardiac operations. J Thorac Cardiovasc Surg 1994;107(3):925-933 